\title{
To evaluate the retinal nerve fiber layer thickness in different types of glaucoma
}

\begin{abstract}
Objective: Glaucoma is a multifaceted eye disease which is classified as physical damage of retinal ganglion cells which may effect in loss of vision and permanent blindness. While physical damage of glaucoma can be clinically evaluated the optic nerve head and peripapillary retinal nerve fiber layer (RNFL). Our objective is to evaluate the mean RNFL thickness in all types of glaucoma.
\end{abstract}

Methodology: This prospective and cross sectional study was conducted in Glaucoma Clinic of Al Ibrahim Eye Hospital (AIEH), Karachi, for the period from May 2019 to October 2019, after ethical approval from Institutional Research Committee. A total of 64 glaucoma patients were chosen by using non-probability purposive sampling technique. The participant comprised, no known eye disease, no visual impairment, IOP below $22 \mathrm{mmHg}$, and no obvious retinal disease or defect were included while individuals having a history of ocular diseases or pathology with residual visual impairment, retinal diseases, amblyopia, and history of intraocular surgery or laser therapy were excluded from the study. The collected data were analyzed using Statistical Package for Social Sciences (SPSS) version 20 .

Results: 64 patients of both genders with mean age of $55.54 \pm 15.58$ years. The mean intraocular pressure of right eye and left eye was $16.46 \pm 8.06$ and $16.75 \pm 7.82 \mathrm{mmHg}$, respectively. The mean RNFL thickness in superior, inferior, temporal and nasal quadrant of the right eye was measured $68.23 \pm 25.44,66.79 \pm 27.50,51.75 \pm 12.58$ and $47.73 \pm 18.82$ microns, respectively while the mean RNFL thickness in superior, inferior, temporal and nasal quadrant of the left eye was measured $76.01 \pm 22.72,67.42 \pm 21.25,54.37 \pm 13.0$ and $49.62 \pm 11.57$ microns, respectively.

Conclusion: Our study showed that analysis of retinal nerve fiber layer thickness with optical coherence tomography is the best tool for the diagnosis of glaucoma. It has also been observed in our study that frequency of changes in retinal nerve fiber layer thickness was mostly found in primary open angle glaucoma patients.

Keywords: glaucoma, central corneal thickness, retinal nerve fiber layer thickness
Volume II Issue I - 202I

\author{
Aqsa Batool,' Shua Azam, ${ }^{2}$ Iqra Nehal, ${ }^{3}$ Areej \\ Riaz, ${ }^{4}$ Muzna Javed, ${ }^{5}$ Tahir Hussain, ${ }^{6}$ Abdul \\ Hameed Talpur ${ }^{7}$ \\ 'Optometrist, pob eye hospital Karachi, Pakistan \\ ${ }^{2}$ Assistant professor, ISRA School of optometry, Al-lbrahim eye \\ hospital, Karachi, Pakistan \\ ${ }^{3}$ Optometrist at Hashmani group of hospitals, Pakistan \\ ${ }^{4}$ Ophthalmologist at pob eye hospitals, FCPS Ophthalmology, \\ Pakistan \\ ${ }^{5}$ Ophthalmologist at pob eye hospital, Pakistan \\ ${ }^{6}$ Instructor at Liaquat College of Medicine and Dentistry, \\ Pakistan \\ ${ }^{7}$ Ophthalmologist, ISRA School of Optometry, Pakistan
}

Correspondence: Shua Azam, Assistant professor, ISRA School of Optometry,Al-Ibrahim Eye Hospital, Karachi, Pakistan, Te 03353092989,Email optomshuaazam@gmail.com

Received: December 30, 2020 | Published: February 25, 2021

\section{Introduction}

Glaucoma is an eye disorder related to enhanced apoptosis of Retinal Ganglion Cells (RGCs). It enhances cupping of the disc of eye and expands thinning of the Retinal Nerve Fiber Layer (RNFL). These physical and structural variations and changes may lead to perimetry changes in optical field. The instruments of eye can increase capability of an eye specialist to identify glaucoma at an initial level to safeguard the loss of vision. According to the worldwide estimations, by the end of 2020 , about $79.6 \mathrm{MN}$ general public may be prone to eye diseases and 11.2 MN patients may be blind. Most of the studies which are based on population revealed that Primary Open Angle Glaucoma (POAG) has become major class of glaucoma therefore its occurrence rates have been turned out to be from $0.5 \%$ to 7.0 $\%$ in adults having the age of 40 and above. The same rates differ according to their races and areas. In general, there are several types of glaucoma but the two main types are very common; Open Angle Glaucoma (OAG) and Angle Closure Glaucoma (ACG) and these glaucoma's are most common in Asia, however, they are also called acute or chronic angle-closure or narrow-angle glaucoma. While, the other forms of glaucoma are Pigmentary glaucoma, Normal-tension glaucoma, Secondary glaucoma, Steroid Induced glaucoma (SIG) etc. are not very common. ${ }^{1-10}$

RNFL thickness of a normal eye means without glaucoma has 80 microns or greater. While, average RNFL thickness of an eye from 70 to 79 microns is considered as doubtful for glaucoma. Evaluation of RNFL thickness has been an imperative for the diagnosis of glaucoma and its monitoring with respect to development as the RNFL encompasses the RGCs axons.

The glaucoma is diagnosed on the basis of changes in optic disc, RNFL, and the standard achromatic perimetry. Physical changes of glaucoma can be identified with different imaging instruments, in which Scanning Laser Polarimetry, Heidelberger Retinal Tomography (HRT), Fundus Photography, and Optical Coherence Tomography (OCT) are included. The OCT is a modern and non-surgical imaging method which evaluates the RNFL thickness of peripapillary in noncontact style in all quadrants. Currently, the OCT is the analysis of macular and optic nerve neuro-retinal rim thickness which have become now very famous, whereas RNFL investigation has become the point of reference and standard of OCT imaging in glaucoma since its beginning. The analysis of RNFL gives substitute to the both visual examination of the optic nerve neuro-retinal rim and a quantitative estimation loss of RGC axonal. It can be very supportive in measuring suspicious glaucoma whose signs and symptoms can be a similar with those of other eye diseases like physiologic cupping and myopia. Various OCT stages give the values of thickness of RNFL at a stable distance from the optic nerve which is around 3.5-mmdiameter, circular, thickness of cross section centered on the nerve of an eye. The thickness of RNFL is normally works on the mechanisms 
of the ISNT principle i.e., inferior, superior, nasal, temporal, and in case if doesn't follow ISNT rule; it can be symptomatic of glaucoma. Secondly, the nasal and temporal quadrants usually require short area, particularly in initial stage of glaucoma, whereas thinning of these quadrants increases the chances of optic neuropathy of nonglaucomatous. ${ }^{11-15}$

In spite of developments in the quality of imaging of SD-OCT, modern OCT tools, and procurement of new instruments, in addition to biological issues can affect the descriptions of measurements of RNFL thickness. Beside of it, length of axial, size of disc, age, gender, neuro-ophthalmic and retinal illnesses, can also affect the thickness of RNFL. The aim of this study was to determine the mean RNFL thickness changes in patients with all types of glaucomatous patients.

\section{Methodology}

This was a prospective, cross sectional study was carried out in Glaucoma Clinic of Al Ibrahim Eye Hospital (AIEH), Karachi. The duration of the study was 6 months from May 2019 to October 2019. Research Ethical Committee (REC) of ISRA Postgraduate Institute of Ophthalmology gave ethical approval. ${ }^{16-25} \mathrm{~A}$ total of 88 eyes of 64 glaucoma patients with the mean age of $55.54 \pm 15.58$ years of both the genders were recruited and monitored for this study using nonprobability purposive sampling technique.

Inclusion criteria for the participants included no visual damage, no known eye disease, no noticeable retinal disease and IOP $<22 \mathrm{~mm}$ of $\mathrm{Hg}$ while individuals having a history of optical diseases with remaining visual injury, retinal infections, amblyopia, and history of intraocular or laser therapy were excluded from the study. All patients were gone through a routine ocular examination, including slit lamp bio-microscopy and ophthalmoscopy. Measurement of IOP, refractive error, best corrected visual acuity (BCVA), central corneal thickness, and vertical and horizontal cup to disc ratio were also measured. Measurements of four quadrants (temporal, superior, nasal, and inferior) RNFL thickness was done by using optical coherence tomography (OCT). Data collected were entered and analyzed by using Statistical Package for Social Sciences (SPSS) version 20 and were presented in the tables by calculating mean, standard mean and deviation for descriptive analysis. It was presented as percentages and frequencies for qualitative variables.

\section{Results}

Table 1 showed that mean age (mean \pm standard deviation) was $55.54 \pm 15.58$ years. For the eyes studied, the mean intraocular pressure of right eye and left eye was $16.46 \pm 8.06$ and $16.75 \pm 7.82$ $\mathrm{mmHg}$, respectively. Mean central corneal thickness of right eye was $381.56 \pm 225.82$ microns while mean central corneal thickness of left eye was $292.14 \pm 252.04$ microns. It was also observed $57.84 \pm 17.78$ microns were the whole thickness of right eye whereas $61.67 \pm 13.92$ microns were the whole thickness of left eye.

The mean RNFL thickness in superior, inferior, temporal and nasal quadrant of the right eye was measured $68.23 \pm 25.44,66.79 \pm 27.50$, $51.75 \pm 12.58$ and $47.73 \pm 18.82$ microns, respectively while the mean RNFL thickness in superior, inferior, temporal and nasal quadrant of the left eye was measured $76.01 \pm 22.72,67.42 \pm 21.25,54.37 \pm 13.0$ and $49.62 \pm 11.57$ microns, respectively. Horizontal cup to disc ratio (mean \pm standard deviation) right and left eye were measured $0.72 \pm 0.08$ $\mathrm{mm} 2$ and $0.73 \pm 0.12$, respectively. Vertical cup to disc ratio (mean \pm standard deviation) right and left eye were measured $0.71 \pm 0.10 \mathrm{~mm} 2$ and $0.75 \pm 0.10$ respectively.
Table I Mean demographic characteristics, intra-ocular pressure, central cornea thickness, retinal nerve fiber layer in four quadrants, and horizontal and vertical cup-to-disc ratio in both eyes

\begin{tabular}{ll}
\hline Variables & Mean \pm SD \\
\hline Age (Years) & $55.54 \pm 15.58$ \\
IOPRE (intraocular pressure right eye) & $16.46 \pm 8.06$ \\
IOPLE (intraocular pressure left eye) & $16.75 \pm 7.82$ \\
$\begin{array}{l}\text { CCTRE (central corneal thickness right eye) } \\
\text { CCTLF (central corneal thickness left eye) }\end{array}$ & $381.56 \pm 225.82$ \\
$\begin{array}{l}\text { WTRE (whole thickness right eye) } \\
\text { WTLE (whole thickness left eye ) }\end{array}$ & $57.84 \pm 17.78$ \\
$\begin{array}{l}\text { RNFL SUPERIOR RE (retinal nerve fiber layer } \\
\text { right eye ) }\end{array}$ & $61.67 \pm 13.92$ \\
$\begin{array}{l}\text { RNFL SUPERIOR LE (retinal nerve fiber layer } \\
\text { left eye) }\end{array}$ & $76.01 \pm 22.72$ \\
$\begin{array}{l}\text { RNFL INFERIOR RE (retinal nerve fiber layer } \\
\text { right eye }\end{array}$ & $66.79 \pm 27.50$ \\
$\begin{array}{l}\text { RNFL INFERIOR LE (retinal nerve fiber layer } \\
\text { left eye }\end{array}$ & $6.44 .42 \pm 21.25$ \\
$\begin{array}{l}\text { RNFL TEMPORAL RE (retinal nerve fiber layer } \\
\text { right eye) }\end{array}$ & $51.75 \pm 12.58$ \\
$\begin{array}{l}\text { RNFL TEMPORAL LE (retinal nerve fiber layer } \\
\text { left eye ) }\end{array}$ & $54.37 \pm 13.0$ \\
$\begin{array}{l}\text { RNFL NASEL RE (retinal nerve fiber layer right } \\
\text { eye) }\end{array}$ & $47.73 \pm 18.82$ \\
$\begin{array}{l}\text { eye ) } \\
\text { CDH RE ( cup-to-disc ratio horizontal right eye) }\end{array}$ & $0.72 \pm 0.08$ \\
\hline
\end{tabular}

Table 2 shows that 34(53.1\%) males were affected and 30(46.9\%) females were affected. More changes in RNFL thickness were measured in 40(62.5\%) cases exhibited POAG (primary open angle glaucoma). Less changes in RNFL thickness were measured in 2(3.1\%) cases exhibited AACG (acute angle closure glaucoma), CACG (chronic angle closure glaucoma), HTG (hypertension glaucoma), PXFG (Pseudoexfoliation glaucoma),6(9.4\%) cases exhibited NVG (neovascularglaucoma), PACG (primary angle closure glaucoma), $4(6.3 \%)$ case exhibited SIG (steroid induced glaucoma). Frequency of Visual acuity $6 / 12$ of right eye was affected by the changes in RNFL thickness in $10(15.6 \%)$, visual acuity $6 / 9$ and $6 / 18$ in $11(17.2 \%)$ cases, $8(12.5 \%)$ cases showed hand movement, $4(6.3 \%)$ cases showed no perception of light. Frequency of Visual acuity 2/60 of left eye was affected by the changes in RNFL thickness in $10(15.6 \%)$, visual acuity $6 / 9$ and $6 / 18$ in $9(14.1 \%)$ cases, $6(9.4 \%)$ cases showed hand movement.

Frequency of right eye affected was observed in 24(37.5\%) cases, frequency of left eye affected was observed in 18(28.1\%) cases and frequency of both eyes affected in 22(34.4\%). Visual acuity was assessed through Snellen visual acuity drum. 
Table 2 Frequency of gender, causes and visual acuity in both eyes. $(n=64)$

\begin{tabular}{|c|c|c|c|}
\hline Variable & & $\mathbf{n}$ & (\%) \\
\hline \multirow[t]{2}{*}{ Gender } & Male & 34 & 53.1 \\
\hline & Female & 30 & 46.9 \\
\hline \multirow[t]{8}{*}{ Cause } & AACG ( acute angle closure glaucoma ) & 2 & 3.1 \\
\hline & CACG ( chronic angle closure glaucoma ) & 2 & 3.1 \\
\hline & HTG ( hypertension glaucoma ) & 2 & 3.1 \\
\hline & NVG ( Neovascular glaucoma ) & 6 & 9.4 \\
\hline & PACG ( primary angle closure glaucoma ) & 6 & 9.4 \\
\hline & POAG ( primary open angle glaucoma ) & 40 & 62.5 \\
\hline & PXFG ( Pseudoexfoliation glaucoma ) & 2 & 3.1 \\
\hline & SIG ( steroid induced glaucoma) & 4 & 6.3 \\
\hline VARE & Jan-60 & 3 & 4.7 \\
\hline \multirow[t]{9}{*}{ (Visual acuity of right eye) } & Feb-60 & 4 & 6.3 \\
\hline & Jun-60 & 4 & 6.3 \\
\hline & 6-Jun & 5 & 7.8 \\
\hline & 9-Jun & 11 & 17.2 \\
\hline & I2-Jun & 10 & 15.6 \\
\hline & I8-Jun & II & 17.2 \\
\hline & 24-Jun & 4 & 6.3 \\
\hline & $\mathrm{H} / \mathrm{M}$ (hand movement) & 8 & 12.5 \\
\hline & NPL ( no perception of light) & 4 & 6.3 \\
\hline VALE & Jan-60 & 12 & 18.8 \\
\hline \multirow[t]{7}{*}{ (Visual acuity of left eye) } & Feb-60 & 10 & 15.6 \\
\hline & Jun-60 & 4 & 6.3 \\
\hline & 9-Jun & 9 & 14.1 \\
\hline & I8-Jun & 9 & 14.1 \\
\hline & 24-Jun & 5 & 7.8 \\
\hline & C/F ( counting fingers) & 9 & 14.1 \\
\hline & $\mathrm{H} / \mathrm{M}$ (hand movement ) & 6 & 9.4 \\
\hline \multirow[t]{3}{*}{ Affected Eye } & R/E ( right eye ) & 24 & 37.5 \\
\hline & L/E ( left eye ) & 18 & 28.1 \\
\hline & B/E ( both eyes) & 22 & 34.4 \\
\hline
\end{tabular}

\section{Discussion}

Glaucoma is a prolonged and growing disease which has been classified as the damage of retinal ganglion cells and axons. RNFL investigation is significant for the diagnosis of glaucoma and monitoring of disease development as it consists of the retinal ganglion cell axons. According to study findings of Khanala $\mathrm{S}$ in normal eyes; $109.8 \pm 8.32$ microns were the mean RNFL thickness whereas $102.0 \pm$ 9.37 microns were suspicious glaucoma, in eyes with NTG the mean RNFL thickness was $85.43 \pm 9.79$ microns and in eyes with POAG the mean was $64.30 \pm 14.45$ microns of RNFL thickness. As far as our study is concerned it is consistent with the above mentioned study. In our results whole thickness of right eye was $57.84 \pm 17.78$ microns and whole thickness of left eye was $61.67 \pm 13.92$ microns which prove that the thinning of RNFL thickness leads to glaucomatous eyes.
One more study revealed that all the quadrants significantly varied in the groups; while only the RNFL thickness of inferior and superior were significantly thinned between normal and Glaucoma Suspect (GS)optics and it may be the reason that the both superior and inferior $\mathrm{ONH}$ poles are the most susceptible and liable to damage of glaucomatous eyes. It has been assumed that these regions may be split areas at the vascular supply junction from adjoining ciliary vessels. Investigation of ultrastructure of the lamina cribrosa indicates that the small holes in the superotemporal and inferotemporal parts are larger and the same bigger pores may bring about the regions more weakest compression. The findings of our study is not consistent with this study as our results show RNFL thickness became thin in temporal and nasal quadrant that was $51.75 \pm 12.58,47.73 \pm 18.82$ in right eye, respectively whereas $54.37 \pm 13.0,49.62 \pm 11.57$ in left eye, respectively. Our results revealed that thickness of RNFL was reduced in temporal and nasal quadrants. 
Another study reported that the division of RNFL thickness in normal eyes was in such a way that the inferior quadrant was the thickest followed by superior, nasal and temporal quadrants. Examination of RNFL thickness in the glaucoma eyes, normal and GS optic shown a specific double hump shape with RNFL peaks in the superior and inferior quadrants and troughs in the nasal and temporal quadrants in all groups, even though this configuration was quite down in glaucomatous eyes, further stressing the greater decline in superior and inferior thickness with more development of glaucomatous loss. This study results are consistent with our study findings in which thickness gradually decreases in the sequence of inferior, superior, temporal and nasal quadrants and following ISTN rule.

As stated by some study, thickness of central cornea plays a main part in the glaucoma diagnosis. One more study based on German population assessed thickness of central corneal in a large number of residents. Mean central corneal thickness (CCT) in the population study was $554.2634 .8 \mathrm{~mm}$. Some more studies have also been reported in other population based research that men have thicker CCT than women. Another study reported that the measurements of CCT are essential when observing patients of glaucoma and ocular hypertensive, as studies have presented that thin CCT is related to greater risk of glaucoma. Our study is not consistent with the above mentioned studies and revealed that central corneal thickness of right and left eye was $381.56 \pm 225.82$ and $292.14 \pm 252.04$, respectively that proves to be declined in central corneal thickness which leads to progressive glaucoma.

One more study explained that vertical cup to disc ratio (VCDR) is normally the most executed clinical examination of the optic disc, which is being adopted for the diagnosis of glaucoma patients. VCDR is well known to differ extensively within the normal populace. In the same study the VCDR is ranged from 0.07 to 0.84 . As far as our study is concerned, these results are similar with our findings in which vertical CDR was $0.71 \pm 0.10$ in the right eye while $0.75 \pm 0.10$ in left eye that was raised from the normal range which supports in the assessment of glaucoma.

One study evaluated and compare the ability of Stratus OCT RNFL, ONH, and macular thickness parameters to detect progressive structural damage in a cohort of patients with glaucoma and individuals with suspected disease observed over time. They included 253 eyes of 253 patients. Among the 253 eyes; 105 (42\%) had glaucoma, and 148 (58\%) were considered to have suspected glaucoma. The average RNFL thickness was significantly lower in progressors compared with nonprogressors and the mean rate of change in RNFL thickness was $-0.72 \mu \mathrm{m} / \mathrm{y}$ in progressors compared with $0.14 \mu \mathrm{m} / \mathrm{y}$ in nonprogressors. They kept a follow-up of two years for the patients while our study collected data only one time to conclude the results.

Measurement of RNFL thickness by OCT, Central Corneal thickness and optic disc change scan help in the diagnosis of early glaucoma. As structural and physical changes may lead to perimetry visual field changes, sensitive imaging instruments and apparatuses can improve clinicians 'aptitude to detect early glaucoma and let welltimed interference to protect vision loss. General practitioners must ponder the possibility of unclear causes and measure data in retinal nerve fiber layer reports within the perspective of the medical image.

\section{Conclusion}

This study concluded that retinal nerve fiber layer investigation with optical coherence tomography is an immensely supportive tool to manage glaucoma patients. It can be used together with other assessment and investigative imaging tools for early diagnosis or pre-perimetric cases, and these measurements are very beneficial to monitor the disease development. This study also concludes that the changes in retinal nerve fiber layer thickness were mostly observed in primary open angle glaucoma.

\section{Acknowledgements}

Special thanks to Professor Dr. Mohammad Saleh Memon, Professor Dr. Sadia Bukhari.

\section{Conflicts of interest}

There are no conflicts of interest.

\section{Funding}

None.

\section{References}

1. Burgoyne $\mathrm{C}$. The morphological difference between glaucoma and other optic neuropathies. J Neuroophthalmol. 2015;35(Suppl 01): S8-S21.

2. Kuang TM, Zhang C, Zangwill LM. Estimating lead time gained by optical coherence tomography in detecting glaucoma before development of visual field defects. Ophthalmology. 2015;122(10):2002-2009.

3. Kyari F, Abdull MM, Bastawrous A, et al. Epidemiology of glaucoma in sub-Saharan Africa: prevalence, incidence and risk factors. Middle East Afr J Ophthalmol. 2013;20(2):111-125.

4. Rudnicka AR, Mt-Isa S, Owen CG, et al. Variations in primary openangle glaucoma prevalence by age, gender, and race: a Bayesian metaanalysis. Invest Ophthalmol Vis Sci. 2006;47:4254-61.

5. Weinreb RN, Aung T, Medeiros FA. The pathophysiology and treatment of glaucoma: a review. JAMA. 2014;311(18):1901-1911.

6. Chauhan BC, O'Leary N, Almobarak FA. Enhanced detection of open-angle glaucoma with an anatomically accurate optical coherence tomography-derived neuroretinal rim parameter. Ophthalmology. 2013;120(3):535-543.

7. Leung CK, Cheung CY, Lin D, et al. Longitudinal variability of optic disc and retinal nerve fiber layer measurements. Invest Ophthalmol Vis Sci. 2008;49(11):4886-4892.

8. Sehi M, Greenfield DS. Assessment of retinal nerve fiber layer using optical coherence tomography and scanning laser polarimetry in progressive glaucomatous optic neuropathy. Am $J$ Ophthalmol. 2006;142(6):1056-1059

9. Sehi M, Iverson SM. Glaucoma Diagnosis and Monitoring Using Advanced Imaging Technologies. US Ophthalmic Rev. 2013;6(1):15-25.

10. Schuman JS, Hee MR, Puliafito CA, et al. Quantification of nerve fiber layer thickness in normal and glaucomatous eyes using optical coherence tomography. Arch Ophthalmol. 1995;113(5):586-596.

11. Gardiner SK, Ren R, Yang H, et al. Method to estimate the amount of neuroretinal rim tissue in glaucoma: comparison with current methods for measuring rim area. Am J Ophthalmol. 2014;157(3): 540-549.

12. Larrosa JM, Moreno-Montañés J, Martinez-de-la-Casa JM, et al. A Diagnostic Calculator for Detecting Glaucoma on the Basis of Retinal Nerve Fiber Layer, Optic Disc, and Retinal Ganglion Cell Analysis by Optical Coherence Tomography. Invest Ophthalmol Vis Sci. 2015;56(11):6788-6795

13. Mwanza JC, Oakley JD, Budenz DL, et al. Cirrus Optical Coherence Tomography Normative Database Study G. Ability of Cirrus HD-OCT 
optic nerve head parameters to discriminate normal from glaucomatous eyes. Ophthalmology. 2011;118(2):241-248.

14. Bussel II, Wollstein G, Schuman JS. OCT for glaucoma diagnosis, screening and detection of glaucoma progression. $\mathrm{Br} J$ Ophthalmol. 2014 Jul;98Suppl 2(2):15-19.

15. Khanala S, Thapaa M, Racetteb L, et al. Retinal nerve fiber laye thickness in glaucomatous Nepalese eyes and its relation with visual field sensitivity. Journal of Optometry. 2014;7:217-224.

16. Quigley HA, Addicks EM, Green WR, et al. Optic nerve damage in human glaucoma. II. The site of injury and susceptibility to damage. Arch Ophthalmol. 1981;99(4):635-49.

17. Morgan JE, Bourtsoukli I, Rajkumar KN. The accuracy of the inferior $>$ superior $>$ nasal $>$ temporal neuroretinal rim area rule for diagnosing glaucomatous optic disc damage. Ophthalmology. 2012;119(4):723-30.

18. Gordon MO, Beiser JA, Brandt JD, et al. The Ocular Hypertension Treatment Study: baseline factors that predict the onset of primary openangle glaucoma. Arch Ophthalmol. 2002Jun;120(6):714-720.

19. Miglior S, Torri V, Zeyen T, et al. Intercurrent factors associated with the development of open-angle glaucoma in the European glaucoma prevention study. Am J Ophthalmol. 2007;144(2):266-275.
20. Hoffmann EM, Lamparter J, Mirshahi A Distribution of central corneal thickness and its association with ocular parameters in a large central European cohort: The Gutenberg health study. PLoS One. 2013;8(8):e66158

21. Vijaya L, George R, Arvind $\mathrm{H}$, et al. Central corneal thickness in adult South Indians: The Chennai Glaucoma Study. Ophthalmology. 2010;117(4): 700-704.

22. Nangia V, Jonas JB, Sinha A, et al. Central corneal thickness and its association with ocular and general parameters in Indians: The Central India Eye and Medical Study. Ophthalmology. 2010;117(4):705-710.

23. Miglior S, Pfeiffer N, Torri V, et al. Predictive factors for open-angle glaucoma among patients with ocular hypertension in the European Glaucoma Prevention Study. Ophthalmology. 2007;114(1):3-9.

24. Miglior S, Zeyen T, Pfeiffer N, et al. Results of the European Glaucoma Prevention Study. Ophthalmology. 2005;112(3):366-375.

25. Crowston JG, Hopley CR, Healey PR, et al. Blue Mountains Eye Study. The effect of optic disc diameter on vertical cup to disc ratio percentiles in a population based cohort: The Blue Mountains Eye Study. $\mathrm{Br} J$ Ophthalmol. 2004;88(6):766-770. 